\title{
Determination of Antibiotic Resistance Pattern and frequency of CTX-M, TEM, and SHV B-Lactamase Encoding Genes among Shigella Isolates from Inpatients in Tehran, Iran
}

Shadi Beladi Ghannadi (MSc) Department of Biology, Faculty of Science, Islamic Azad University Islamshahr Branch, Islamshahr, Iran Maryam Ghane (PhD)

Department of Biology, Faculty of Science, Islamic Azad University Islamshahr Branch, Islamshahr, Iran Laleh Babaeekhou (PhD) Department of Biology, Faculty of Science, Islamic Azad University Islamshahr Branch, Islamshahr, Iran Corresponding author: Maryam Ghane

Email: ghane@iiau.ac.ir Tel: +98-2156358105

Address: Islamic Azad University, Islamshahr Branch, Islamshahr, Iran

Received: 9 Jun 2018

Revised: 02 Dec 2018

Accepted: 2 Dec 2018 (c) (i) (8)

This work is licensed under a Creative Commons Attribution 4.0 License.

\section{ABSTRACT}

Background and 0bjectives: The emergence of extended-spectrum $\beta$-lactamase (ESBL)-producing Shigella spp. is becoming a health concern worldwide. This study aimed to investigate antibiotic resistance pattern and frequency of bla $a_{\mathrm{CTX}-\mathrm{N}}, b a_{\mathrm{SH}}$, and $b a_{\mathrm{TEN}}$ genes among Shigella isolates from patients in hospitals of Tehran, Iran.

Methods: In this cross-sectional study, 52 non-repeated Shigella strains were isolated from hospitalized patients in Milad, Emam Khomeini and Shariati hospitals in Tehran (Iran) from November 2015 to December 2016. Bacterial identification, serotyping, and antimicrobial susceptibility testing were performed according to the standard guidelines. The bla $a_{\mathrm{CTX}-\mu}, b a_{\mathrm{SH}}$, and $b a_{\mathrm{TEN}}$ resistance genes were identified using multiplex polymerase chain reaction.

Results: Among 52 Shigella isolates, S. sonnei (44.2\%) was the predominant species, followed by $S$. flexneri and $S$. dysenteriae (23\%). 0ver $67 \%$ of the isolates were multidrug resistant. The highest rates of resistance were observed against cefalotin (67.3\%), tetracycline (67.3\%), amikacin (63.5\%), trimethoprim-sulphamethoxazole (40.1), and ampicillin (42.3\%). The lowest resistance rate was against ciprofloxacin (1.9\%). We detected the bla $a_{\text {ТЕ }}$ and $b a_{\text {СТХ-и }}$ genes in $61.5 \%$ and $19.2 \%$ of the isolates, respectively. However, the bla $a_{\text {SHV }}$ gene was not detected in any of the isolates. In addition, $16.4 \%$ of the isolates harbored the bla $a_{\text {TЕ॥ }}$ and bla $a_{\text {СTX-॥ }}$ genes simultaneously. Ciprofloxacin was the most effective antibiotics according to the ESBL genes distribution.

Conclusion: 0ur findings indicate the high prevalence of multidrug resistance and ESBL genes in Shigella isolates, which elucidates the need for appropriate infection control measures for limiting the spread of resistant strains.

Keywords: Shigella, Multiplex Polymerase Chain Reaction, Drug Resistance.

This paper should be cited as: Beladi Ghannadi SH, Ghane M, Babaeekhou L[Determination of Antibiotic Resistance Pattern and frequency of CTX-M, TEM, and SHV B-Lactamase Encoding Genes among Shigella Isolates from Inpatients in Tehran, Iran]. mljgoums. 2019; 13(2):8- 15 


\section{INTRODUCTION}

Shigellosis is a global human health problem and the leading cause of diarrhea, which results in about 700,000 deaths per year worldwide (1). Despite the recent public health improvements, incidence of shigellosis is still being reported regularly $(2,3)$. The genus Shigella belongs to the Enterobacteriaceae family and consists of four subgroups according to their biochemical and serological properties: A (Shigella dysenteriae), B (Shigella flexneri), C (Shigella boydii), and D (Shigella sonnei). All Shigella species can cause shigellosis, but $S$. flexneri and $S$. sonnei are the predominant causative agents in developing and industrialized countries, respectively (4).

Antibiotic therapy in patients with shigellosis can help reduce the duration of illness, shedding of the organism in the feces, and the risk of person-to-person spread. A range of antibiotics is effective for the treatment of shigellosis. However, treatment options are limited due to the emergence of multidrugresistant (MDR) strains. The World Health Organization (WHO) has recommended ciprofloxacin as the first-line treatment (5), but increased resistance to this antibiotic and other fluoroquinolones has been reported in many countries (2, 6). Azithromycin, mecillinam, and ceftriaxone are also considered to be effective for treatment of shigellosis (5).

The emergence of resistance to thirdgeneration cephalosporins (3GC) in Shigella spp. is an important public health concern, mainly in developing countries (7). Resistance to 3GC is largely due to production of extended-spectrum $\beta$-lactamases (ESBLs), which is often plasmid-mediated (8). Most ESBLs are derivatives of the TEM and SHV $\beta$ lactamase families, but CTX-M $\beta$-lactamases have also been associated with ESBLproducing strains. These $\beta$-lactamases show greater activity against cefotaxime than ceftazidime, but increased activity against ceftazidime can occur due to point mutations (9).

CTX-M, SHV, and TEM type ESBL producing Shigella species have been identified in different parts of the world $(6,8$, 10). Studies on ESBL-producing Shigella isolates have revealed presence of insertion element upstream of the $b l a_{\text {CTX-M }}$ gene, which may contribute to the mobility and dissemination of the genes $t o$ other bacteria
(8). The frequency of ESBL- producing Shigella species is increasing in Iran $(11,12)$. According to studies in Iran, the prevalence of ESBL-producing Shigella strains is higher than the rates observed in many other countries $(11,13)$. Studying the role of these isolates in infectivity and continuous monitoring of ESBL genes may be beneficial for determining appropriate treatment and control strategies in Iran. Therefore, the present study was conducted to evaluate antibiotic susceptibility profiles and to screen the presence of $b l a_{\mathrm{TEM}}, b l a_{\mathrm{CTX}-\mathrm{M}}$, and $b l a_{\mathrm{SHV}}$ genes among clinical isolates of Shigella.

\section{MATERIALS AND METHODS}

This cross-sectional study was conducted between November 2015 and December 2016 at three teaching hospitals in Tehran, Iran. Stool samples were collected from patients admitted with symptoms of diarrhea prior to administration of antibiotics. Samples were immediately transferred to laboratory and then inoculated on xylose lysine deoxycholate agar (Merck, Germany). The plates were incubated at $37{ }^{\circ} \mathrm{C}$ for 24 hours and then Shigella suspected colonies were examined by conventional biochemical tests, including triple sugar iron agar, urea agar, SIM medium and IMVIC (indole, methyl red, Voges-Proskauer, and citrate) (14). Specific antisera (DIFCO, U.S.A) were used for serogrouping of Shigella isolates using a slide agglutination test (15). The study was approved by the Ethics Committee of Islamic Azad University of Tehran Medical Sciences (No: IR.IAU.TMU.REC.1396.275).

Antibiotic susceptibility testing was performed using the Kirby-Bauer disk diffusion method, according to CLSI guidelines (2017). The following antibiotic disks were used in the susceptibility testing: amikacin $(30 \mu \mathrm{g})$, tetracycline $(30 \mu \mathrm{g})$, nalidixic acid $(30 \mu \mathrm{g})$, ciprofloxacin $(5 \mu \mathrm{g})$, furazolidone $(100 \mu \mathrm{g})$, cefolatin $(30 \mu \mathrm{g})$, doxycycline $(30 \mu \mathrm{l})$, trimethoprim-sulfamethoxazole $(25 \mu \mathrm{g})$, cefazolin $(30 \mu \mathrm{g})$, gentamicin $(120 \mu \mathrm{g})$, ceftriaxone $(30 \mu \mathrm{g})$, and ceftazidime $(30 \mu \mathrm{g})$ (Mast Diagnostics, UK). In addition, E. coli ATCC 25922 was used as the control strain (16). To confirm ESBL production, combination disk test using cefotaxime and ceftazidime disks $(30 \mu \mathrm{g})$ with and without clavulanic acid $(10 \mu \mathrm{g})$ was carried out on 
Mueller Hinton agar (Merck, Germany) according to CLSI guidelines. Growth inhibition zone around cefotaxime or ceftazidime disks combined with clavulanic acid was compared with that around cefotaxime or ceftazidime disks alone. Growth inhibition zone diameter of $>5 \mathrm{~mm}$ with clavulanic acid than without confirmed ESBL production (16).

Boiling method was used for extraction of DNA from pure colonies after an overnight growth of Shigella isolates on Luria-Bertani agar (Oxoid, UK). Concentration of the extracted DNA was assessed by a spectrophotometer (Genway, England). Multiplex polymerase chain reaction (PCR) was performed using specific primers for simultaneous detection of the $b l a_{\mathrm{SHV}}, b l a_{\mathrm{CTX}-\mathrm{M}}$, and $b l a_{\text {TEM }}$ (Table 1). PCR reactions were carried out in a final volume of $25 \mu \mathrm{l}$ containing $2 \mu \mathrm{l}$ DNA solution, Master Mix (CinnaGen Co., Iran), and 10 pmol of each primer. PCR amplification conditions were as follows: initial denaturation at $95{ }^{\circ} \mathrm{C}$ for 15 min, 30 cycles of denaturation at $94{ }^{\circ} \mathrm{C}$ for 30 $\mathrm{s}$, annealing at $60{ }^{\circ} \mathrm{C}$ for $30 \mathrm{~s}$, extension at 72 ${ }^{\circ} \mathrm{C}$ for $2 \mathrm{~min}$, followed by final extension at 72 ${ }^{\circ} \mathrm{C}$ for $10 \mathrm{~min}$ (17). Klebsiella pneumoniae ATCC 700603 was used as positive control. SPSS statistical software (version 20; SPSS Inc., Chicago, IL, USA) was used for data analysis. The chi-square test was used to evaluate significant differences in antimicrobial resistance and the correlation between resistance genes and antibiotics resistance. A P-value of less than 0.05 was considered statistically significant.

\section{RESULTS}

Of 945 samples collected during the study period, 52 Shigella strains were isolated. Among these isolates, S. sonnei was the predominant species $(\mathrm{n}=23,44.2 \%)$, followed by $S$. flexneri $(\mathrm{n}=12,23 \%), S$. dysenteriae $(\mathrm{n}=12,23 \%)$, and $S$. boydii $(\mathrm{n}=5,9.6 \%)$. Figure 1 shows the antimicrobial resistance patterns of Shigella isolates against the tested antibiotics. Highest rate of resistance was against cefalotin (67.3\%), tetracycline (67.3\%), amikacin (63.47\%), trimethoprimsulphamethoxazole (48.1), ampicillin (42.3\%), and doxycycline $(32.7 \%)$. Moderate to low rate of resistance was observed against nalidixic acid (23.1\%), ceftriaxone (19.2\%), azithromycin (11.5), ceftazidime (9.6\%), gentamicin $(11.5 \%)$, and ciprofloxacin $(1.9 \%)$. The isolates showed intermediate resistance to doxycycline $(26.9 \%)$, trimethoprimsulphamethoxazole $(23.1 \%)$, cefazoline (17.3\%), and gentamicin (17.3\%). All Shigella isolates were resistant to nalidixic acid, but all $S$. flexneri, $S$. dysenteriae, and $S$. boydii isolates were sensitive to ciprofloxacin.

Table 1- Sequence of the primers used in multiplex PCR

\begin{tabular}{ccc}
\hline Genes & Oligonucleotide sequence (5' to 3') & Amplicon size (bp) \\
\hline bla $_{\mathrm{SHV}}$ & ATGCGTTATATTCGCCTGTG & References \\
bla $_{\mathrm{TEM}}$ & TGCTTTGTTATTCGGGCCAA & $(18)$ \\
bla $_{\mathrm{CTX}-\mathrm{M}}$ & TCGCCGCATACACTATTCTCAGAATGA & \\
& ACGCTCACCGGCTCCAGATTTAT & \\
& ATGTGCAGCACCAGTAAAGTGATGGC & \\
& TGGGTAAAGTAAGTGACCAGAATCAGCGG & \\
\hline
\end{tabular}

Figure 1-Antibiotic susceptibility pattern of Shigella isolates to various antibiotics. Tri/Sul*: trimethoprim/sulfamethoxazole

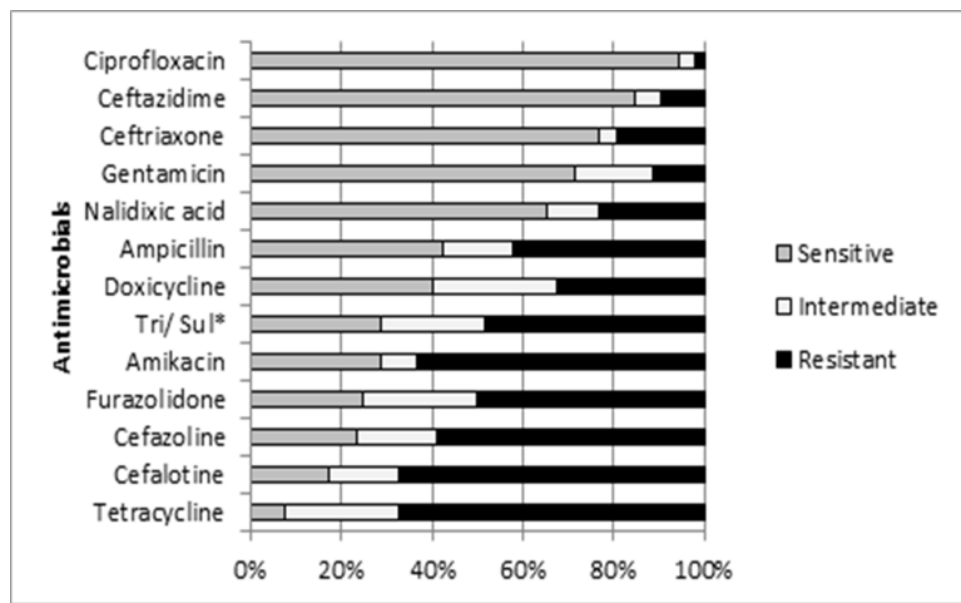


Strains resistant to three or more classes of antibiotics were identified as MDR (20). Multidrug resistance was detected in 15 (65.2\%) S. sonnei, 10 (83.3\%) S. dysenteriae, $8(66.6 \%)$ S. flexneri, and 1 (20\%) S. boydii isolates.

Multidrug resistance profiles of Shigella isolates are reported in Table 3. Phenotypic evidence of ESBL production was observed in 19 (36.5\%) Shigella isolates, among which $S$. dysenteriae $(7 / 12, \quad 58.3 \%)$ was the predominant ESBL producer, followed by $S$. flexneri $(4 / 12,33.3 \%), \quad S$. sonnei (7/23, $30.4 \%)$, and $S$. boydii $(1 / 5,20 \%)$.
All 52 Shigella isolates were also tested for the presence of the $b l a_{\mathrm{TEM}}, b l a_{\mathrm{SHV}}$, and $b l a_{\mathrm{CTX}-\mathrm{M}}$ genes. All isolates were negative for $b l a_{\mathrm{SHV}}$, but $32(61.54 \%)$ isolates harbored bla $a_{\mathrm{TEM}}$. Ten $(19.23 \%)$ isolates contained $b l a_{\text {CTX-M }}$ and seven isolates $(13.46 \%)$ carried both bla $a_{\mathrm{TEM}}$ and $b l a_{\text {СтХ-м. }}$. Figure 2 displays the PCR gel electrophoresis of the $b l a_{\mathrm{TEM}}, b l a_{\mathrm{CTX}-\mathrm{M}}$, and $b l a_{\mathrm{SHV}}$ genes. The frequency of $b l a_{\mathrm{TEM}}$ was highest in S. dysenteriae (83.3\%), followed by S. sonnei $(60.87 \%)$. However, the frequency of simultaneous harboring of $b l a_{\mathrm{TEM}}$ and $b l a_{\mathrm{CTX}-\mathrm{M}}$ was highest among $S$. sonnei isolates (Figure $3)$.

Figure 2- Multiplex PCR assay for detection of bla $_{\mathrm{TEM}}$, bla $a_{\mathrm{CTX}-\mathrm{M}}$, and $b_{\mathrm{SHV}}$ on $1.5 \%$ agarose gel. Lane 1: negative control, lane 2-4: positive for bla $_{\mathrm{TEM}}$ and bla $_{\mathrm{CTX}-\mathrm{M}}$, lane 5-7: positive for bla $_{\mathrm{TEM}}$, lane 8-10: positive for bla $a_{\mathrm{CTX}-\mathrm{M}}$, and lane 11: positive control ( $K$. pneumoniae ATCC 700603).

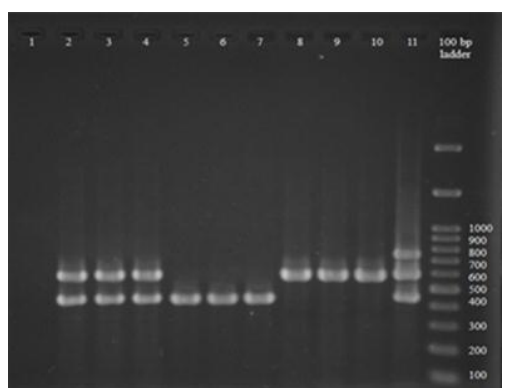

Figure 3- Frequency of the $b l a_{\mathrm{TEM}}, b_{a_{\mathrm{CTX}-\mathrm{M}}}$ and $b l a_{\mathrm{SHV}}$ genes in Shigella isolates

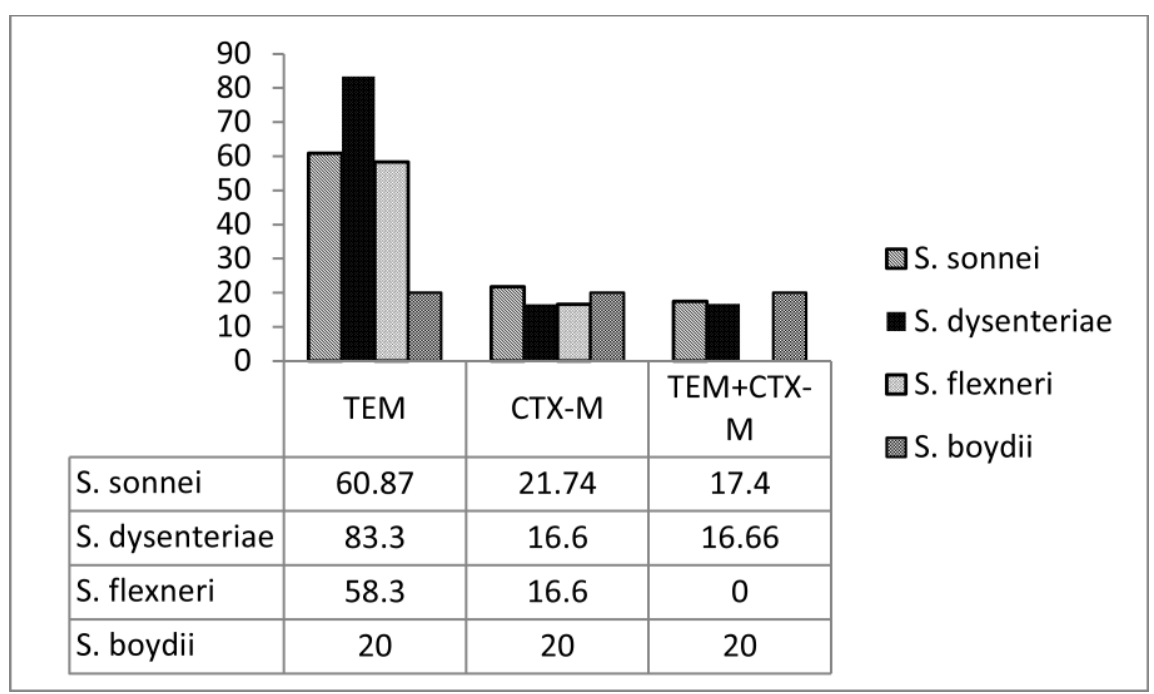

All MDR Shigella strains carried at least one bla gene (Table 3). The results showed that all bla TEM$^{-c o n t a i n i n g ~ S h i g e l l a ~ s t r a i n s ~ w e r e ~}$ resistant to cefalotin, $75 \%$ were resistant to tetracycline, amikacin, and cefazolin, $72 \%$ were resistant to trimethoprimsulfamethoxazole, and $55.5 \%$ were resistant to ampicillin and furazolidone. All Shigella strains that simultaneously carried $b l a_{\mathrm{TEM}}$ and $b l a_{\text {СтХ-м }}$ were resistant to ampicillin, amikacin, tetracycline, nalidixic acid, furazolidone, cefalotin, doxycycline, trimethoprimsulfamethoxazole, cefazolin, and ceftriaxone. Furthermore, only one strain harboring both $b l a_{\mathrm{TEM}}$ and $b l a_{\mathrm{CTX}-\mathrm{M}}$ was resistant to ciprofloxacin (Table 2 ). 
Table 2- Multidrug resistance profile of Shigella isolates $(\mathrm{n}=35)$ based on the distribution of bla genes

\begin{tabular}{|c|c|c|c|c|c|c|}
\hline Antimicrobial resistance profiles & & & \%) of resistant i & & & ESBL genes \\
\hline & Total $(\mathbf{n}=\mathbf{3 4})$ & $\begin{array}{c}\begin{array}{c}\text { S. sonnei } \\
(\mathrm{n}=15)\end{array} \\
\text { (n) }\end{array}$ & $\begin{array}{c}\text { S. dysenteriae } \\
(\mathrm{n}=10)\end{array}$ & $\begin{array}{l}\text { S. flexneri } \\
(\mathrm{n}=8)\end{array}$ & $\begin{array}{c}\text { S. boydii } \\
(\mathrm{n}=1)\end{array}$ & \\
\hline $\mathbf{A K} / \mathbf{T} / \mathbf{K F}$ & $1(2.9)$ & $\mathbf{0}$ & $1(10)$ & $\mathbf{0}$ & $\mathbf{0}$ & $b l a_{\mathrm{TEM}}$ \\
\hline $\mathrm{AK} / \mathrm{T} / \mathrm{FZ} / \mathrm{KF}$ & $1(2.9)$ & $1(6.7)$ & $\mathbf{0}$ & $\mathbf{0}$ & $\mathbf{0}$ & $b l a_{\mathrm{TEM}}$ \\
\hline $\mathrm{AK} / \mathrm{T} / \mathrm{KF} / \mathrm{TS} / \mathrm{CZ}$ & $3(8.8)$ & o & $1(10)$ & $2(25)$ & $\mathbf{0}$ & $b l a_{\mathrm{TEM}}$ \\
\hline $\mathrm{AP} / \mathrm{AK} / \mathrm{T} / \mathrm{KF} / \mathrm{CZ}$ & $1(2.9)$ & $\mathbf{0}$ & $1(10)$ & $\mathbf{0}$ & $\mathbf{0}$ & $b^{\prime} a_{\mathrm{TEM}}$ \\
\hline $\mathbf{A K} / \mathbf{T} / \mathbf{F Z} / \mathbf{K F} / \mathbf{C Z}$ & $2(5.9)$ & $2(13.3)$ & 0 & $\mathbf{0}$ & $\mathbf{0}$ & bla $_{\mathrm{TEM}}$ \\
\hline AK/T/FZ/KF/TS & $1(2.9)$ & 0 & $1(10)$ & $\mathbf{0}$ & $\mathbf{0}$ & bla $_{\mathrm{TEM}}$ \\
\hline AP/AK/T/NA/KF & $1(2.9)$ & $1(6.7)$ & $\mathbf{0}$ & $\mathbf{0}$ & $\mathbf{0}$ & $b l a_{\mathrm{TEM}}$ \\
\hline FZ/KF/DX/TS/CZ & $1(2.9)$ & $1(6.7)$ & $\mathbf{0}$ & $\mathbf{0}$ & $\mathbf{0}$ & $b l a_{\mathrm{TEM}}$ \\
\hline $\mathrm{AK} / \mathrm{T} / \mathrm{KF} / \mathrm{CZ} / \mathrm{CRO}$ & $1(2.9)$ & $1(6.7)$ & $\mathbf{0}$ & $\mathbf{0}$ & $\mathbf{0}$ & $b^{\prime} a_{\mathrm{TEM}}$ \\
\hline FZ/KF/DX/CZ/CRO & $1(2.9)$ & $1(6.7)$ & $\mathbf{0}$ & $\mathbf{0}$ & $\mathbf{0}$ & $b l a_{\text {CTX-M }}$ \\
\hline $\mathrm{AP} / \mathrm{AK} / \mathrm{T} / \mathrm{FZ} / \mathrm{KF} / \mathrm{CZ}$ & $1(2.9)$ & $1(6.7)$ & $\mathbf{0}$ & $\mathbf{0}$ & $\mathbf{0}$ & $b^{\prime} a_{\mathrm{TEM}}$ \\
\hline $\mathrm{AP} / \mathrm{AK} / \mathrm{T} / / \mathrm{KF} / \mathrm{TS} / \mathrm{CZ}$ & $1(2.9)$ & 0 & $\mathbf{0}$ & $1(12.5)$ & $\mathbf{0}$ & $b^{\prime a} a_{\mathrm{TEM}}$ \\
\hline $\mathrm{AK} / \mathrm{T} / \mathrm{FZ} / \mathrm{KF} / \mathrm{TS} / \mathrm{CZ}$ & $1(2.9)$ & $\mathbf{0}$ & $\mathbf{0}$ & $1(12.5)$ & $\mathbf{0}$ & bla $_{\mathrm{TEM}}$ \\
\hline $\mathrm{AK} / \mathrm{T} / \mathrm{KF} / \mathrm{DX} / \mathrm{TS} / \mathrm{CZ}$ & $1(2.9)$ & $\mathbf{0}$ & $\mathbf{0}$ & $1(12.5)$ & $\mathbf{0}$ & $b l a_{\mathrm{TEM}}$ \\
\hline AP/AK/T/FZ/KF/TS/CZ & $4(11.8)$ & $2(13.3)$ & $1(10)$ & $1(12.5)$ & $\mathbf{0}$ & $b l a_{\mathrm{TEM}}$ \\
\hline $\mathrm{AP} / \mathrm{AK} / \mathrm{T} / \mathrm{FZ} / \mathrm{KF} / \mathrm{DX} / \mathrm{TS} / \mathrm{CZ}$ & $2(5.9)$ & $\mathbf{0}$ & $2(20)$ & $\mathbf{0}$ & $\mathbf{0}$ & $b l a_{\mathrm{TEM}}$ \\
\hline AP/AK/T/NA/FZ/KF/TS/CZ/ & $1(2.9)$ & $\mathbf{0}$ & $1(10)$ & $\mathbf{0}$ & $\mathbf{0}$ & $b l a_{\mathrm{TEM}}$ \\
\hline AP/AK/T/NA/FZ/KF/DX/TS/CZ & $1(2.9)$ & $1(6.7)$ & $\mathbf{0}$ & $\mathbf{0}$ & $\mathbf{0}$ & $b^{\prime} a_{\mathrm{TEM}}$ \\
\hline AP/AK/T/NA/FZ/KF/DX/TS/CZ/CRO & $1(2.9)$ & o & $1(10)$ & $\mathbf{0}$ & $\mathbf{0}$ & $b l a_{\mathrm{TEM}} ; b l a_{\mathrm{CTX}-\mathrm{M}}$ \\
\hline AP/AK/T/NA/FZ/KF/DX/TS/CZ/GM/CRO & $2(5.9)$ & $\mathbf{0}$ & 0 & $2(25)$ & $\mathbf{0}$ & bla $_{\text {CTX-M }}$ \\
\hline $\mathrm{AP} / \mathrm{AK} / \mathrm{T} / \mathrm{NA} / \mathrm{FZ} / \mathrm{KF} / \mathrm{DX} / \mathrm{TS} / \mathrm{CZ} / \mathrm{CRO} / \mathrm{CZA}$ & $1(2.9)$ & $1(6.7)$ & $\mathbf{0}$ & $\mathbf{0}$ & $\mathbf{0}$ & $b l a_{\mathrm{TEM}} ; b l a_{\mathrm{CTX}-\mathrm{M}}$ \\
\hline AP/AK/T/NA/FZ/KF/DX/TS/GM/CRO & $1(2.9)$ & 0 & $1(10)$ & $\mathbf{0}$ & $\mathbf{0}$ & $b l a_{\mathrm{TEM}} ; b l a_{\text {СТХ-M }}$ \\
\hline $\mathrm{AP} / \mathrm{AK} / \mathrm{T} / \mathrm{NA} / \mathrm{FZ} / \mathrm{KF} / \mathrm{DX} / \mathrm{TS} / \mathrm{CZ} / \mathrm{CRO} / \mathrm{CZA}$ & $1(2.9)$ & $1(6.7)$ & $\mathbf{0}$ & $\mathbf{0}$ & $\mathbf{0}$ & $b l a_{\mathrm{TEM}} ; b l a_{\mathrm{CTX}-\mathrm{M}}$ \\
\hline $\mathrm{AP} / \mathrm{AK} / \mathrm{T} / \mathrm{NA} / \mathrm{FZ} / \mathrm{KF} / \mathrm{DX} / \mathrm{TS} / \mathrm{CZ} / \mathrm{GM} / \mathrm{CRO} / \mathrm{CZA}$ & $1(2.9)$ & $\mathbf{0}$ & $\mathbf{0}$ & $\mathbf{0}$ & $1(100)$ & $b l a_{\mathrm{TEM}} ; b l a_{\mathrm{CTX}-\mathrm{M}}$ \\
\hline AP/AK/T/NA/CIP/FZ/KF/DX/TS/CZ/GM/CRO/CZA & $2(5.9)$ & $2(13.3)$ & $\mathbf{0}$ & $\mathbf{0}$ & $\mathbf{0}$ & $b l a_{\mathrm{TEM}} ; b l a_{\mathrm{CTX}-\mathrm{M}}$ \\
\hline
\end{tabular}

AK: amikacin, T: tetracycline, NA: nalidixic acid, C: ciprofloxacin, FZ: furazolidone, KF: cefolatin, DXT: doxycycline, TS: trimethoprim-sulfamethoxazole, CZ: cefazolin, GM: gentamicin, CRO: ceftriaxone, and CZA: ceftazidime. 


\section{DISCUSSION}

Shigellosis is a major cause of morbidity and mortality among children in the developing countries (21). MDR Shigella isolates narrow the choice of effective antimicrobials and treatment options for shigellosis (22). Besides, with the advent of ESBL-producing Shigella strains, 3GC is no longer effective against MDR Shigella. Hence, knowledge about the contribution of the MDR strains to infectivity in hospitalized patients and continuous monitoring of the involved genes in different regions can be beneficial for development and implementation of preventive and control measures.

$S$. sonnei and $S$. flexneri are the most commonly isolated species in industrialized (23) and developing countries (24), respectively. In our study, S. sonnei was the most common cause of shigellosis, which is consistent with findings of other studies in Iran (25-27). Reasons behind the dominance of $S$. sonnei in industrialized countries remain unclear (28), but an increasing incidence of shigellosis caused by $S$. sonnei generally correlates with improving economic prosperity (29).

In our study, most Shigella isolates were resistant and intermediately resistant to trimethoprim-sulfamethoxazole and ampicillin, the first-line drugs suggested by the CLSI for shigellosis (30). These results are in line with the results of other studies $(31,32)$. Quinolones are a good choice for the treatment of shigellosis (30). However, more than $34 \%$ of Shigella isolates in our study were resistant and intermediately resistant to nalidixic acid. In a study by Ghavam et al. in Iran, a similar frequency for resistance to nalidixic acid was observed (26), but in some countries higher resistance rates have been reported $(7,31)$.

Multi-drug resistance to the antimicrobial agents used for the treatment of shigellosis has been reported in many parts of the world (31, $33,34)$. The results of our study suggest that multidrug resistance is common amongst all Shigella species, and this property was more notable in the case of $S$. dysentrie. Inappropriate prescription and the easy access to antibiotics among outpatients could facilitate the spread of MDR Shigella strains in the community (34).

In the case of infections caused by MDR strains, 3GC and fluoroquinolones are used for treatment of children and adults, respectively
(35). We detected very little resistance to ciprofloxacin (1.92\%), which is comparable with the results of other studies in Iran $(12,27$, 36). However, a higher prevalence for ciprofloxacin-resistant Shigella isolates has been documented in other countries $(31,33$, 34). In our study, the rate of resistance to ceftriaxone was $19.23 \%$, which is higher than the rates reported by studies in Iran $(11,27$, $37)$ and other countries $(31,38)$. However, even higher prevalence rates for ceftriaxone resistance among Shigella isolates has been reported in China (39). We also observed simultaneous resistance to ciprofloxacin and ceftriaxone, which further limits therapeutic options.

In a study by Pourakbari and colleagues, $S$. sonnei was more sensitive to cephalosporines (ceftizoxime, ceftriaxone, ceftazidime, and cephalothin) than S. flexneri, and S. flexneri was more sensitive to nalidixic acid than $S$. sonnei (40). Contrary to these findings, we found no significant difference in antibiotic susceptibility among $S$. sonnei and $S$. flexneri isolates.

In recent years, a high frequency of TEM gene has been identified in Shigella and other Enterobacteriaceae (22). This is of great clinical importance because the gene confers resistance to ampicillin, which was the principal antibiotic used for treatment of shigellosis (41). In our study, the bla $a_{\text {TEM }}$ gene was detected in $61.5 \%$ of the Shigella isolates and in all MDR strains. Ampicillin resistance was found to be significantly associated with TEM $\beta$-lactamase genes in all isolates, which is in agreement with the results of other studies $(10,42)$. Ampicillin resistance in S. flexneri and $S$. sonnei is mainly due to the presence of $b l a_{\mathrm{OXA}}$ and $b l a_{\mathrm{TEM}}$, respectively (42). Likewise, we found a significant correlation between ampicillin resistance and presence of $b l a_{\mathrm{TEM}}$ in $S$. sonnei isolates. However, no significant relationship was found between resistance to ampicillin and presence of $b l a_{\mathrm{TEM}}$ in S. flexneri isolates.

In the present study, the frequency of $b l a_{\text {СTX-M }}$ was relatively high among Shigella isolates. Zahedi Bialvaei et al. reported an even higher frequency for the $b l a_{\text {CTX-M }}$ gene (12). Among the Shigella isolates, $b l a_{\text {СтХ-м }}$ was more frequently found in S. sonnei $(21.74 \%)$, which is higher $(33,43)$ and in one case lower (23) 


\section{CONCLUSION}

than the frequencies reported by studies in other countries. This could be because the transfer of the bla $a_{\text {СтX-м }}$ gene is plasmidmediated.

To the best of our knowledge, this is the first report on the emergence of simultaneous resistance to ceftriaxone and ciprofloxacin among bla $_{\text {СТХ-м}}$-positive Shigella isolates in Iran. With the increase in globalization, the potential widespread dissemination of these strains could be a public health threat, not only in Iran but also in the rest of the world. Therefore, effective infection control policies are needed for preventing the dissemination of resistant strains. Phage- based control of shigellosis can be considered as an alternative strategy for the treatment of MDR Shigella strains (44).

\section{REFERENCES}

1. Tai AY, Easton M, Encena J, Rotty J, Valcanis M, Howden BP, et al. A review of the public health management of shigellosis in Australia in the era of culture independent diagnostic testing. Aust N Z J Public Health. 2016; 40: 588-91.

2. Kim JS, Kim JJ, Kim SJ, Jeon SE, Seo KY, Choi JK, et al. Outbreak of Ciprofloxacin-Resistant Shigella sonnei Associated with Travel to Vietnam, Republic of Korea. Emerg Infect Dis. 2015; 21(7): 1247-50.

3. Kozyreva VK, Jospin G, Greninger AL, Watt JP, Eisen JA, Chaturvedi V. Recent Outbreaks of Shigellosis in California caused by two distinct populations of Shigella sonnei with either increased virulence or fluoroquinolone resistance. $\mathrm{mSphere.} \mathrm{2016;21;1(6).} \mathrm{doi:}$ 10.1128/mSphere.00344-16.

4. Livio S, Strockbine NA, Panchalingam S, Tennant SM, Barry EM, Marohn ME, et al. Shigella isolates from the global enteric multicenter study inform vaccine development. Clin Infect Dis. 2014; 59 (7): 933-41.

5. World Health Organization. Guidelines for the Control of. Shigellosis, including epidemics due to Shigella dysenteriae type 1. Geneva: WHO; 2005.

6. Qiu S, Xu X, Wang Y, Yang G, Wang Z, Wang H, et al. Emergence of resistance to fluoroquinolones and third-generation cephalosporins in Shigella flexneri subserotype $1 c$ isolates from China. Clin Microbiol Infect. 2012 ;18 (4): E95-8. doi: 10.1111/j.14690691.2012.03768.x.

7. Zhang R, Zhou HW, Cai JC, Zhang J, Chen GX, Nasu $\mathrm{M}$, et al. Serotypes and extended-spectrum $\beta$-lactamase types of clinical isolates of Shigella spp. from the Zhejiang province of China. Diagn Microbiol Infect Dis. 2011; 69: 98-104.

8. Sabra AH, Araj GF, Kattar MM, Abi-Rached RY, Khairallah MT, Klena JD, et al. Molecular characterization of ESBL-producing Shigella sonnei isolates from patients with bacilliary dysentery in Lebanon. J Infect Dev Ctries. 2009; 3(4): 300-05.
We revealed the high prevalence of $b l a_{\text {TEM }}$ and $b l a_{\text {СTX-м }}$ in Shigella strains isolated from patients in Iran. Antimicrobial susceptibility testing also demonstrated the high level of multi-drug resistance among these isolates. These findings raise serious concerns about the dissemination of ESBLproducing Shigella strains, and emphasize the need for controlled use of antibiotics, especially $3 \mathrm{GC}$, to avoid further antibiotic resistance.

\section{ACKNOWLEDGEMENTS}

This article has been derived from an MSc thesis, funded by the Islamic Azad University, Islamshahr Branch, Iran.

\section{CONFLICT OF INTEREST}

The authors declare that there is no conflict of interest.

9. Manoharan A, Premalatha K, Chatterjee S, Mathai D. Correlation of TEM, SHV and CTX-M extendedspectrum beta lactamases among Enterobacteriaceae with their in vitro an $\neg$ timicrobial susceptibility. Indian J Med Microbiol. 2011; 29(2): 161-4.

10. Taneja N, Mewara A, Kumar A, Verma G, Sharma M. Cephalosporin-resistant Shigella flexneri over 9 years (2001-09) in India. J Antimicrob Chemother. 2012; 67: 1347-53.

11. Ranjbar R, Mirsaeed Ghazi F, Shohreh Farshad S, Giammanco GM, Aleo A, Owlia P, et al. The occurrence of extended-spectrum $\beta$-lactamase producing Shigella spp. in Tehran, Iran. Iran J Microbiol. 2013; 5 (2): 108112 .

12. Zahedi Bialvaei A, Pourlak T, Aghamali M, Asgharzadeh M, Gholizadeh P, Samadi Kafil H. The prevalence of CTX-M-15 extended spectrum $\beta$ lactamases among Salmonella spp. and Shigella spp. isolated from three Iraninan hospitals. Eur J Microbiol Immunol. 2017; 7(2): 133-7.

13. Akhi MT, Bialvaei A, Ghotaslou R, Asgharzadeh M, Naghili B, Pirzadeh T, et al. Faecal carriage of ESBL and plasmidmediated AmpC $\beta$-lactamase genes in Klebsiella spp. and Shigella spp. isolated from inpatient and outpatient carriers in Tabriz, Iran. Int J Fund Appl Sci. 2016; 8: 16-29.

14. Barrow GI, Feltham RKA. Cowan and Steel's Manual for the Identification of Medical Bacteria. Cambridge University Press, 2005.

15. Lefebvre J, Gosselin F, Ismaïl J, Lorange M, Lior H, Woodward D. Evaluation of commercial antisera for Shigella serogrouping. J Clin Microbiol. 1995; 33(8): 1997-2001.

16. Wayne P. Performance standards for antimicrobial susceptibility testing. Clinical and Laboratory Standards Institute (CLSI) 27th informational supplement M100, 2017. 
17. Monstain HJ, Ostholm- Balkhed A, Nilsson MV, Nilsson M, Dornbusch K, Nilsson LE. Multiplex amplification assay for detection of blaSHV, blaTEM and blaCTX-m genes in Enterobacteriaceae. APMIS. 2007; 115: $1400-8$.

18. Paterson DL, Hujer KM, Hujer AM, Yeiser B, Bonomo MD, Rice LB, et al. Extendedspectrum $b$ lactamases in Klebsiella pneumonia bloodstream isolates from seven countries: dominance and widespread prevalence of SHV-and CTX-M-type b-lactamases. Antimicrob Agents Chemother. 2003; 47: 3553-60.

19. Boyd DA, Tyler S, Christianson S, McGeer A, Muller MP, Willey BM, et al. Complete nucleotide sequence of a 92-kilobase plasmid harboring the CTXM-15 extended-spectrum beta-lactamase involved in an outbreak in long-term-care facilities in Toronto, Canada. Antimicrob Agents Chemother. 2004; 48: 3758-64.

20. Magiorakos AP, Srinivasan A, Carey RB, Carmeli Y, Falagas ME, Giske CG, et al. Multidrug-resistant, extensively drug-resistant and pandrug-resistant bacteria: an international expert proposal for interim standard definitions for acquired resistance. Clin Microbiol Infect. 2012; 18: 268-81.

21. Gupta S, Mishra B, Muralidharan S, Srinivasa H. Ceftriaxone resistant Shigella flexneri, an emerging problem. Ind J Med Sci. 2010; 64: 553-6.

22. Yang C, Li P, Zhang X, Ma Q, Cui X, Li H, et al. Molecular characterization and analysis of high-level multidrug-resistance of Shigella flexneri serotype $4 \mathrm{~s}$ strains from China. Sci Rep. 2016; 6: 29124. doi: 10.1038/srep29124.

23. Zhang CL, Liu QZ, Wang J, Chu X, Shen LM, Guo YY. Epidemic and virulence characteristic of Shigella spp. with extended-spectrum cephalosporin resistance in Xiaoshan District, Hangzhou, China. BMC Infect Dis. 2014; 14: 260. doi: 10.1186/1471-2334-14-260.

24. Sethuvel DPM, Rajupathi NKD, Anandan S, Veeraraghavan B. Update on: Shigella new serogroups/serotypes and their antimicrobial resistance. Lett Appl Microbiol 2016; 64: 8-18.

25. Alizadeh-Hesar M, Bakhshi B, Najar-Peerayeh S. Clonal dissemination of a single Shigella sonnei strain among Iranian children during fall 2012 in Tehran, I.R. Iran. Infect Genet Evol. 2015; 34: 260-6.

26. Ghavam P, Monajemzadeh M, Haghi Ashtiani M T, Mamishi S, Nodeh Farahani N, Tanzifi P. Shigellosis and Changes of Antimicrobial Susceptibility During Six Years. Iran J Pediatr. 2017; 27(3): e5131. doi: 10.5812/ijp.5131.

27. Tajbakhsh M, García Migura L, Rahbar M, Svendsen CA, Mohammadzadeh M, et al. Antimicrobial resistant Shigella infections from Iran: an overlooked problem? J Antimicrob Chemother.2012; 67(5): 1128-33.

28. Keusch GT. Bacterial Infections of Humans. Brachman PS, Abrutyn E, editors Boston, MA: Springer US, 2009.

29. Ram P, Crump J, Gupta S, Miller M, Mintz E. Part II. Analysis of data gaps pertaining to Shigella infections in low and medium human development index countries, 1984-2005. Epidemiol Infect. 2008; 136: 577-603.

30. Wayne P. Performance standards for antimicrobial susceptibility testing. Clinical and Laboratory Standards Institute (CLSI) 16th informational supplement M100S16, 2006.
31. Aggarwal P, Uppal B, Ghosh R, Krishna Prakash S, Chakravarti A, Jha AK, et al. Multi drug resistance and extended spectrum beta lactamases in clinical isolates of Shigella: A study from New Delhi, India. Travel Medicine and Infectious Disease. 2016; 14(4): 407-13.

32. Shiferaw B, Solghan S, Palmer A, Joyce K, Barzilay EJ, Krueger A, et al. Antimicrobial susceptibility patterns of Shigella isolates in foodborne diseases active surveillance network (FoodNet) sites, 2000-2010. Clin Infect Dis. 2012; 54(5): 458-63.

33. Nüesch-Inderbinen M, Heini N, Zurfluh K, Althaus D, Hächler H, Stephan R. Shigella antimicrobial drug resistance mechanisms, 2004-2014. Emerg Infect Dis. 2016; 22(6): 1083-5.

34. Zhang W, Luo Y, Li J, Lin L, Ma Y, Hu C, et al. Wide dissemination of multidrug-resistant Shigella isolates in China. J Antimicrob Chemother. 2011; 66: 2527-35.

35. Acikgoz ZC, Eser OK, Kocagoz S. CTX-M-3 type beta-lactamase producing Shigella sonnei isolates from pediatric bacillary dysentery cases. Jpn J Infect Dis. 2008; 61: 135-7.

36. Nikfar R, Shamsizadeh A, Darbor M, Khaghani1 S, Moghaddam M. A Study of prevalence of Shigella species and antimicrobial resistance patterns in paediatric medical center in Ahvaz, Iran. Iran $\mathrm{j}$ microbial. 2017; 9(5): 277-82.

37. Khaghani S, Shamsizadeh A, Nikfar R, Hesami A. Shigella flexneri: a three-year antimicrobial resistance monitoring of isolates in a Children Hospital, Ahvaz, Iran. Iran j microbial. 2014; 6(4): 225-9.

38. Zaidi MB, Estrada-García T, Campos FD, Chim R, Arjona $\mathrm{F}$, Leon $\mathrm{M}$, et al. Incidence, clinical presentation, and antimicrobial resistance trends in Salmonella and Shigella infections from children in Yucatan, Mexico. Front Microbiol. 2013; 4: 288. doi: 10.3389/fmicb.2013.00288.

39. Cui X, Yang C, Wang J, Liang B, Yi S, Li H, et al. Antimicrobial Resistance of Shigella flexneri Serotype $1 \mathrm{~b}$ Isolates in China. PLOS ONE 2015; 10(6): e0129009. doi: 10.1371/journal.pone.0129009.

40. Pourakbari B, Mamishi S, Mashoori N, Mahboobi N, Ashtiani MH, Afsharpaiman S, et al. Frequency and antimicrobial susceptibility of Shigella species isolated in Children Medical Center Hospital, Tehran, Iran, 2001-2006. Braz J Infect Dis. 2010; 14(2): 153-7.

41. Klontz KC, Singh N. Treatment of drug-resistant Shigella infections. Expert Rev Anti Infect Ther. 2015; 13: 69-80.

42. Toro CS, Farfan M, Contreras I, Flores O, Navarro $\mathrm{N}$, Mora GC, et al. Genetic analysis of antibiotic resistance determinants in multidrug-resistant Shigella strains isolated from Chilean children. Epidemiol Infect. 2005; 133: 81-6.

43. Kacmaz B, Unaldi O, Sultan N, Durmaz R. Drug resistance profiles and clonality of sporadic Shigella sonnei isolates in Ankara, Turkey. Braz J Microbiol. 2014; 45(3): 845-9.

44. Shahin K, Bouzari M, Wang R. Isolation, characterization and genomic analysis of a novel lytic bacteriophage $v$ B_SsoS-ISFOO2 infecting Shigella sonnei and Shigella flexneri. J Med Microbiol. 2018; 67(3): 376-386. 